UNIVERSITÀ CATTOLICA DEL SACRO CUORE

Dipartimento di Economia e Finanza

\author{
Working Paper Series
}

Electoral Cycle Bias in the Media Coverage of Corruption News

Marco Le Moglie and Gilberto Turati

Working Paper n. 69

April 2018

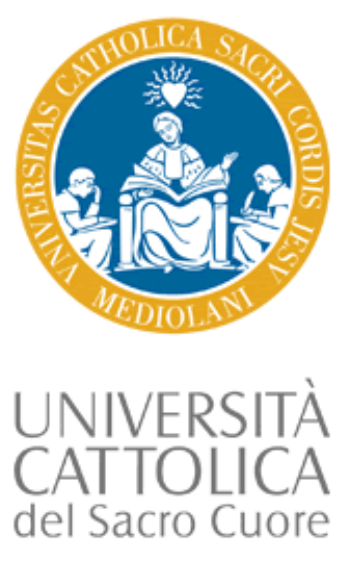




\title{
Electoral Cycle Bias in the Media Coverage of Corruption News
}

\author{
Marco Le Moglie \\ Università L. Bocconi \\ Gilberto Turati \\ Università Cattolica del Sacro Cuore
}

Working Paper n. 69

April 2018

\begin{abstract}
Dipartimento di Economia e Finanza Università Cattolica del Sacro Cuore Largo Gemelli 1 - 20123 Milano - Italy tel: +39.02.7234.2976 - fax: +39.02.7234.2781

e-mail: dip.economiaefinanza@unicatt.it
\end{abstract}

The Working Paper Series promotes the circulation of research results produced by the members and affiliates of the Dipartimento di Economia e Finanza, with the aim of encouraging their dissemination and discussion. Results may be in a preliminary or advanced stage. The Dipartimento di Economia e Finanza is part of the Dipartimenti e Istituti di Scienze Economiche (DISCE) of the Università Cattolica del Sacro Cuore. 


\title{
Electoral Cycle Bias in the Media Coverage of Corruption
}

\section{News}

\author{
Marco Le Moglie*† \\ Gilberto Turati ${ }^{\ddagger}$ \\ Bocconi University \\ Catholic University
}

\begin{abstract}
We investigate the existence of an 'electoral cycle bias' in the timing of media coverage of news with high political value. In particular, we analyze how the electoral cycles at the regional level influence the coverage of news about corruption scandals in the Italian Regional Health Systems by two important national newspapers having opposite ideology, La Repubblica (left-wing oriented) and Il Giornale (right-wing oriented). Our findings show that $\mathrm{Il}$ Giornale produces more articles about corruption scandals involving left-wing politicians in the days right before the elections, while it reduces the number of those about right episodes of corruption and without any political connection. Instead, for La Repubblica we do not find any evidence of the existence of neither an electoral cycle, nor an ideological bias in the coverage of corruption. These results are robust to different model specifications, the potential endogeneity of some elections, and different measures of the time to the elections.
\end{abstract}

JEL classification: D72, D73, H51, H75, K42, L82

Keywords: media, media bias, electoral cycle, ideology, corruption scandals, health system, Italian regions.

${ }^{*}$ We would like to thank Marina Di Giacomo, Maria Petrova, Massimiliano Piacenza, Paola Profeta, Francesco Sobbrio, Giuseppe Sorrenti and David Stadelmann for their comments on earlier drafts of this work. The paper is part of a research project on integrity and legality in the health care sector managed by Coripe Piemonte and financed by the Compagnia di San Paolo. The usual disclaimers apply.

${ }^{\dagger}$ Department of Policy Analysis and Public Management and DONDEN, Bocconi University Milan, Italy. E-mail: marco.lemoglie@unibocconi.it

${ }^{\ddagger}$ Corresponding author. Department of Economics and Finance, Catholic University, Rome, Italy. Email: gilberto.turati@unicatt.it 


\section{Introduction}

Do media faithfully report misconduct of elected officials? Or do they silence political scandals? As watchdogs of political institutions, the role of media is certainly crucial for the proper working of a democracy. But, in recent years, the growing importance of media in everyday life has gone hand in hand with a decline in political involvement and participation by citizens, a 'media-democracy paradox' which has been originated also by the changing role of the media system (McChesney, 2015). Increasingly powerful commercial media firms may be not dedicated exclusively to watchdog journalism in their coverage of politically relevant news for different reasons (Entman, 2012; Gratton et al., 2017). First, since profits are positively influenced by the number of readers or viewers, supply of news could be driven by users' preferences, leading media to cover more easyto-consume news to the detriment of information more important for the accountability of the political system but less attractive for the public (Ho and Liu, 2015; Sen and Yildirim, 2015). However, media outlets could have their own ideological stance, which implies a bias in the supply of political news affecting the selection of both the topic to be covered and how it is presented and discussed (Mullainathan and Shleifer, 2005; Gentzkow and Shapiro, 2010).

In this paper we are interested in understanding whether media try to affect voters' opinions when these matter most, much like incumbent politicians try to do increasing for instance more visible categories of public spending when elections get closer. In particular, we study if, and how, the coverage of politically relevant news by media outlets varies with respect to the electoral cycle, a dimension of media bias so far left unexplored by the literature. To identify this 'electoral cycle bias' in politically relevant news, we build a new original database containing all the articles about corruption scandals related to public health care in the Italian regions published during the period 2002-2014. We consider news about corruption in public health care since these are the most salient for voters in regional elections, as long as health spending is by far the most important item in regional budgets in Italy (about $75 \%$ of total spending). As for media, we focus on the behavior of two of the most important Italian newspapers, La Repubblica and Il Giornale, and we analyze how 
the production of articles about corruption varies according to the regional electoral cycles, the newspaper's ideology, and their interaction. We choose La Repubblica and Il Giornale since, among the Italian national newspapers, they are - in a slightly different manner both those with a clear political stance and those with the highest diffusion among the individuals sharing the same political view, which makes them the reference newspapers for the median left-wing and right-wing voter respectively.

There are at least two reasons of why the coverage of these politically salient news by media may change with the electoral cycle. On the one hand, since the informational value of corruption news for readers is likely to be higher before than after the elections, when voters are assessing new candidates and the performance of incumbents, the demand for politically relevant news will also be higher in pre-election period (a demand-side effect). On the other hand, however, since the media has its own ideological stance, the supply of political news may be affected also by this bias, especially if the content of the news may have important political consequences (a supply-side effect).

The analysis of how the coverage of news about corruption scandals varies with respect to electoral cycles represents an ideal setting for testing the interaction between demandand supply-side effects. Our findings - which are robust with respect to different model specifications, the potential endogeneity of some elections, and to different measures of the time to the elections - suggest the presence of a 'partisan electoral cycle' only for $\mathrm{Il}$ Giornale. In particular, Il Giornale produces significantly more articles about corruption scandals involving left-wing politicians in election times than in other periods (about 38\% of its standard deviation in the daily number of articles about left episodes of corruption), and at the same time it reduces the coverage of those involving right-wing politicians (about $55 \%$ of its standard deviation for this type of episodes), or those involving any political party (around $150 \%$ of its standard deviation for this type of episodes). On the contrary, even if it seems to report about corruption episodes more than Il Giornale, the coverage of corruption scandals by La Repubblica does not appear to be significantly affected neither by the electoral cycle, nor by its ideology. We argue that these differences between the two newspapers are mainly due to the different number of readers and the different degree of 
ideological polarization of these readers. Furthermore, while we can only provide anecdotal evidence on the political consequences of newspapers' behavior, we believe our findings can help shed additional light on recently discovered 'corruption cycles' (Sidorkin and Vorobyev, 2017).

The remainder of the paper is organized as follows. Section 1 briefly reviews the relevant literature, Section 2 presents our new dataset with some descriptives, whereas in Section 3 we describe the empirical strategy. In Section 4 we discuss the results and in Section 5 we check their robustness. Finally, Section 6 provides some final remarks.

\section{Literature review}

As the theoretical literature on political budget cycles suggests, incumbent politicians try to influence voters' behavior in different ways as the elections gets nearer. ${ }^{1}$ First, to increase their chances of being reelected, they might reduce unemployment in pre-election years as in the original contribution by Nordhaus (1975); second, they might pursue an expansionary budgetary policy to signal their competence to voters before elections as in Rogoff and Sibert (1988), Rogoff (1990) and Shi and Svensson (2006); or they might decide to target pivotal groups of voters by increasing specific categories of spending (e.g. Drazen and Eslava (2010), Potrafke (2010) and Klomp and De Haan (2013)). Empirical evidence on these arguments - surveyed, e.g., in De Haan (2013) - indicates that political budget cycles are more likely to occur in younger than in more mature democracies, even though the mechanism driving the result is far from clear: some authors, for instance, hint at the role of media in providing correct information to the electorate (e.g. Brender and Drazen (2006) and Shi and Svensson (2006)). Additionally, whether these strategies bring real benefits to incumbent politicians is still an under-researched area, and the evidence is mixed (De Haan, 2013) .

While public spending and deficit are considered as variables that should positively affect voters' opinions about incumbent politicians, similar arguments could be made in relation

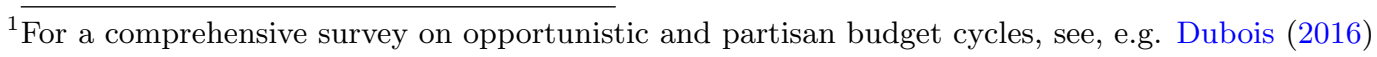


to variables that are evaluated negatively by voters. For instance, in countries where corruption is common practice, abstaining from bribes before elections could also be a strategy available to elected officials to gain more votes. This argument should give rise to corruption cycles in countries where politicians are elected, ${ }^{2}$ but this would be true only if corruption is detected and made public as soon as an official receives bribes. However, corruption is unobservable, people have perceptions about the level of corruption in public life, and perceptions are driven also by the media coverage reporting about corruption episodes.

As discussed in the Introduction, also media are strategic players in this game, and they should take into account users' preferences on the one hand, but also have their own ideology on the other hand (especially if media owners are the politicians themselves). The existence of a bias in media reporting is investigated by a recent strand of literature in political economy. ${ }^{3}$ This bias might be related to the several dimensions on which newspapers can operate an ideological selection: the issue to be covered (Duggan and Martinelli, 2011; Di Tella and Franceschelli, 2011; Larcinese et al., 2011; Puglisi and Snyder, 2011), which aspects of the issue to highlight or exclude (Alaoui and Germano, 2012), how to present and discuss the facts (Gentzkow and Shapiro, 2010; Hassett and Lott., 2014), and how to select the sources of the news (Sobbrio, 2014a). The bias can originate from both the supply- and (or) the demand-side of the market for news. On the supply side, media owners (Duggan and Martinelli, 2011; Di Tella and Franceschelli, 2011), as well as editors and journalists (Baron, 2006), might have incentives to bias the coverage of news according to their own ideology, or simply to get private benefits. For instance, Gentzkow et al. (2006) show how the importance of such incentives depends on how much profits the media would lose (from both advertising and circulation) by biasing the news coverage. On the demand-side, since media outlets are profit maximizing agents, they might bias the news coverage in order to attract as many readers as possible to increase their revenues.

2 On an empirical exercise on corruption cycles in Russia, a country where politicians are instead appointed, see, e.g., Sidorkin and Vorobyev (2017)

${ }^{3}$ See Prat and Strömberg (2013) and Sobbrio (2014b) for a complete review of the many findings, theoretical and empirical, produced by the political economy of mass media literature. 
This is especially true in a context in which readers are affected by cognitive biases. For instance, the presence of a confirmation bias - affecting the way in which individuals generally elaborate information - might lead the media to select both the news to be published (Mullainathan and Shleifer, 2005) and its own sources of information (Sobbrio, 2014a). However, also in the presence of a perfectly rational audience, the incentives to bias could originate both from a reputational game among media outlets to attract more readers (Gentzkow and Shapiro, 2006), or from the limitations of the communication technology offered by newspapers (Chan and Suen, 2008).

The empirical literature on this topic, mainly on the US, suggests the importance of both the demand- and the supply-side of the market for news, depending on the dimension of the bias and the way in which this is measured. For instance, findings by Gentzkow and Shapiro (2010) show that newspapers biasing their own vocabulary towards the rightwing do circulate more within areas recording a higher presence of Republican voters, thus providing a strong positive evidence in favor of the demand-side story. Instead, Puglisi and Snyder (2011) provide a more heterogeneous picture, finding that actually the supply-side story plays a crucial role in determining the bias in the coverage of political scandals by US newspapers. In particular, newspapers more likely to endorse the Democratic party at the elections give more coverage of scandals involving Republicans, while the reverse is true for Republican-leaning newspapers. However, newspapers follow readers' specific preferences in the coverage of local scandals, regardless of their own political position, signaling a definitively more important role for the demand-side story in this case.

In this paper we contribute to this literature on media bias by providing a first analysis of a new dimension on which the ideological bias in the coverage of news by media can take place, that is the timing of coverage. We also provide additional evidence of an important element for the political budget cycle literature, as media reporting of what politicians actually do is likely to affect voters' perceptions even with respect to variables like public spending and deficit. 


\section{Media coverage of corruption scandals in the Italian NHS}

In order to test the existence of an 'electoral cycle bias' in the media coverage of news about corruption scandals, we focus on episodes concerning the Italian regions and related to the National Health System (NHS) published during the period 2002-2014. The main reason for this choice is the importance for voters in regional elections of news concerning corruption practices in their Regional Health System. Indeed, according to Constitutional rules, the Italian NHS is a regional system that assign to regions the ultimate responsibility of managing (and partly funding) health care services, and health care spending represents by far the largest share in regional expenditures (Turati, 2013). While differences in per capita spending are mitigated by an allocation formula accounting for needs, with central government redistributing resources toward less fiscally autonomous regions, there is a large variability across regions in terms of both inefficient and inappropriate spending (Francese et al., 2014; Piacenza and Turati, 2014). Corruption is part of the inefficient spending, but is definitely less well known and studied.

Here we consider an original database counting the number of articles on cases of corruption, involving or not politicians, produced by two important Italian nationwide newspapers, $L a$ Repubblica and Il Giornale, that are also characterized by a clear ideological orientation. On the one hand, La Repubblica was founded in 1976 and since its origins it has chosen to place itself within the Italian secular and reformist left ${ }^{4}$; since 1987 it has been one of the most read Italian newspaper at national level. ${ }^{5}$ On the other hand, Il Giornale was created in 1974, with a more centrist attitude than La Repubblica, but as soon as its new owner, Mr. Silvio Berlusconi ${ }^{6}$, decided to enter into politics in 1994 it started assuming political positions definitively closer to the Italian right-wing parties, Mr. Berlusconi being the leader of right-wing parties during the last 20 years. In terms of the size of its

\footnotetext{
${ }^{4}$ The name of the newspaper is a tribute to a small Portuguese newspaper (República), controlled by its own workers, which provided influential information during the "Carnation" revolution in Portugal in 1974.

${ }^{5}$ It has alternated the first place with Il Corriere della Sera.

${ }^{6}$ Actually, he became the greatest shareholder of the company controlling $\mathrm{Il}$ Giornale (Societá Europea di Edizioni S.p.A.) in 1979, but up to his decision to enter into politics, which occurred in 1994, he had never openly interfered with the editorial line of the newspaper, which was always consistent with its original centrism.
} 
readership, although it is the biggest among the national right-wing leaning newspapers, it is dramatically smaller than for La Repubblica, accounting on average for less than half of the size of the readership of this newspaper. ${ }^{7}$

The articles are selected from the Factiva archive by applying a specific searching procedure by sensitive keywords, which is described in details in the Appendix A. The Factiva archive is a commercial database containing the production of several national and international media outlets, among which also the two Italian newspapers considered in our analysis, since the beginning of their digitalisation, corresponding to 2005 for La Repubblica and to 2002 for Il Giornale. Once selected the articles, we determine: the specific case of corruption discussed, the Italian region which it refers to, the newspaper producing it and the publishing date. Then, for each case, still using the information contained in the articles, we determine whether it involves left-wing politicians, right-wing politicians or any political party. Finally, for all the days in which at least an article is observed, we calculate the total number of articles about corruption scandals published by newspaper, region and political affiliation of the individuals involved in scandals.

At the end of this procedure we collected 1296 articles about 155 different corruption scandals related to the NHS published by the two Italian newspapers, corresponding to 1058 daily observations within the period 2002-2014, that is on average an article each 3.7 days and 1.2 articles per each observation. Among 155 corruption scandals, 19 involve left-wing politicians, 40 right-wing politicians while 96 any political party.

Figure 1 presents the geographical distribution of the corruption scandals across Italian regions, differentiated by the political orientation of people involved.

The highest number of corruption scandals involving left-wing politicians are recorded in Puglia (8 cases) and Calabria (4 cases); the highest number of cases involving right-wing politicians is in Lombardia (15 cases) and Lazio (6 cases); while the greatest number of scandals without any political connection is recorded in Puglia (21 cases) and Campania (16 cases).

\footnotetext{
${ }^{7}$ According to data provided by Agenzia Diffusione Stampa $(A D S)$, the authority certifying the data about the diffusion of the Italian newspapers, the average number of copies daily sold during the period 2002-2014 is around 484,000 for La Repubblica and slightly more than 177,000 for Il Giornale.
} 


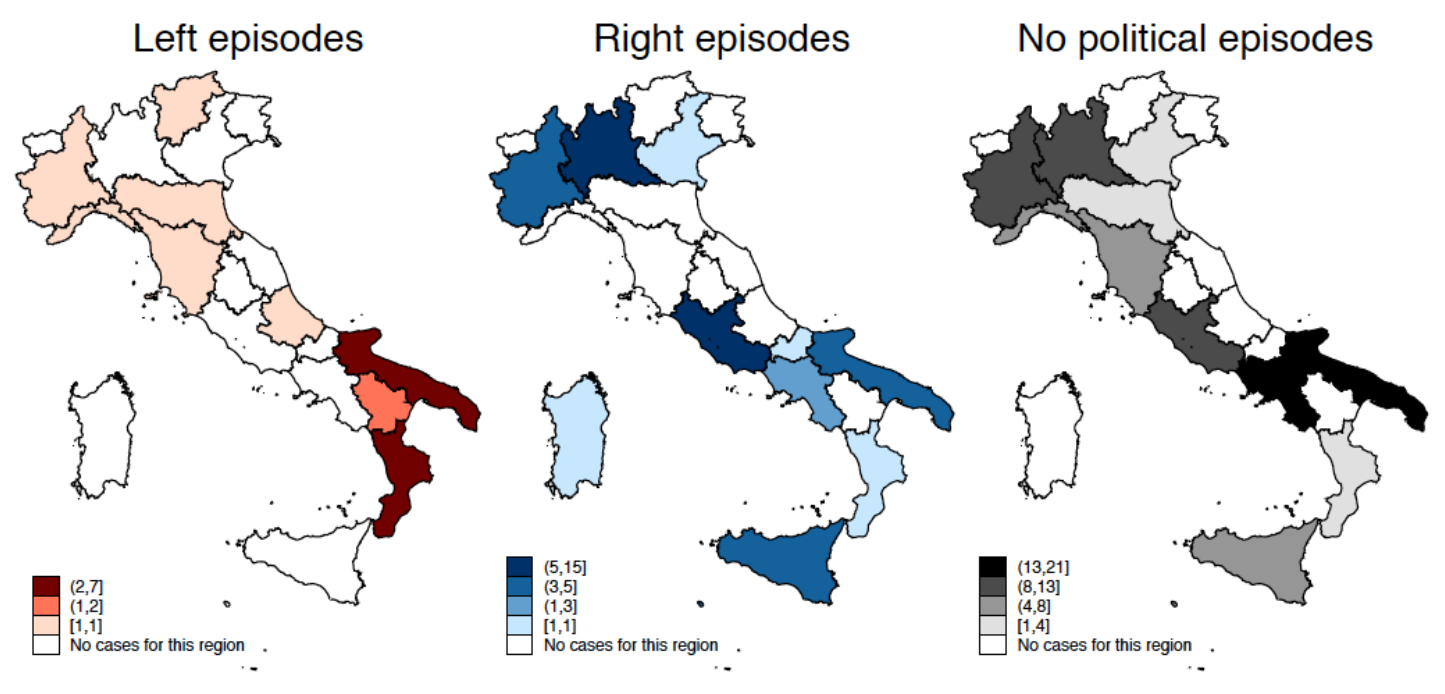

Figure 1: Geographical distribution of corruption scandals.

Note: The maps show the geographical distribution of the cases of corruption scandals in the Italian regions related to the NHS reported from 2002 to 2014, disentangled by political orientation of the individuals involved in the scandals. 
Table 1 shows additional descriptive statistics about the distribution of the articles by newspapers and political orientation of the individuals involved in the scandals.

\begin{tabular}{lcccc}
\hline \hline & \multicolumn{5}{c}{ La Repubblica } \\
\hline & Left episodes & Right episodes & NP episodes & Total \\
Number of articles & 307 & 346 & 308 & 961 \\
Average number of articles per observation & 0.40 & 0.45 & 0.40 & 1.23 \\
S.D. of the number of articles per observation & 0.66 & 0.68 & 0.70 & 0.62 \\
Maximum number of articles per observation & 4 & 5 & 6 & 6 \\
\hline & Left episodes & Right episodes & NP episodes & Total \\
& 96 & 113 & 126 & 335 \\
Number of articles & 0.34 & 0.40 & 0.45 & 1.19 \\
Average number of articles per observation & 0.55 & 0.65 & 0.74 & 0.61 \\
S.D. of the number of articles per observation & 3 & 4 & 6 & 7 \\
Maximum number of articles per observation & 3 & \multicolumn{2}{c}{ Giornale } \\
\hline \hline
\end{tabular}

Table 1: Summary statistics.

Note: The table shows the total number of articles about corruption scandals related to the NHS in the Italian regions, the total number of daily observations, the average, the standard deviation (S.D.) and the maximum number of articles per observation, all disentangled by newspaper and political orientation of the individuals involved in the scandals.

La Repubblica produces in general more articles about corruption scandals than Il Giornale, regardless of the political orientation of the people involved, and despite the shorter observational window within the Factiva archive for the former than for the latter. Such differences could be due to a general stronger attention this newspaper pays to corruption, but also to the higher number of pages making La Repubblica ${ }^{8}$, allowing for a higher number of articles published in the same issue. Indeed, by looking at the total distribution of the number of articles for each observation, it is easy to see that the differences between the two newspapers are dramatically reduced, with La Repubblica publishing on average 1.23 articles per episode of corruption with a standard deviation (S.D.) of 0.40, while $\mathrm{Il}$ Giornale 1.19 articles with a S.D. of 0.45. With respect to the political orientation of the corruption scandals, La Repubblica seems to publish in absolute terms slightly more articles about right episodes of corruption, while $\mathrm{Il}$ Giornale writes more about episodes

${ }_{8}^{8}$ According to our calculations on the information provided by the Factiva archive, the average number of pages of La Repubblica over the time interval considered in this analysis is 60, while for Il Giornale is 40. 

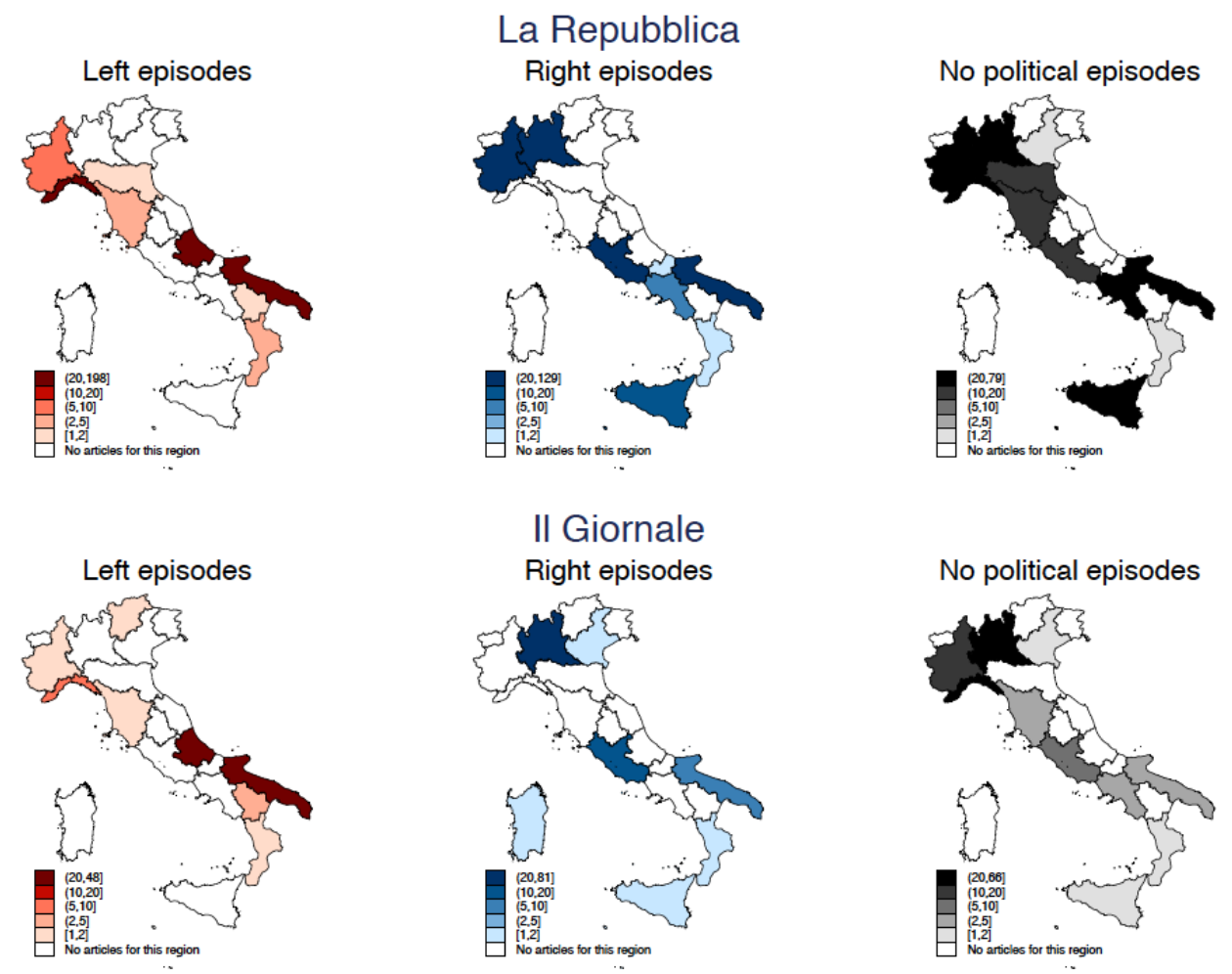

Figure 2: Geographical distribution of the articles about corruption scandals.

Note: The maps show the geographical distribution of the cases of corruption scandals in the Italian regions related to the NHS, as produced by La Repubblica (upper part) and Il Giornale (bottom part) from 2002 to 2014 and further disentangled by political orientation of the individuals involved in the scandals.

not involving politicians.

Figure 2 maps the geographical distribution of the articles over the Italian territory for the two newspapers.

Most of the articles produced by La Repubblica about left episodes of corruption refer to Abruzzo, Liguria and Puglia, those about right-episodes mostly relate to Lombardia, Lazio, Piemonte and Puglia, while those not involving political parties are definitively more numerous, including half of the Italian regions. Instead, according to the maps in the bottom panel of Figure 2, Il Giornale confirms a general lower propensity to publish news about corruption, focusing only on Puglia and Abruzzo for the left episodes of corruption, 
in Lombardia for the right episodes and on Liguria and Lombardia for those without any political connection.

\section{$3 \quad$ Empirical strategy}

The aim of this work is to assess whether there exists an 'electoral cycle bias' in the coverage of news with high political value by newspapers and how this interacts with the ideological stance of the papers. The choice to focus on news about corruption scandals related to the NHS in the Italian regions is motivated by the fact that these news are very important for the readers' to assess the performance of politicians and political parties at the local level, and we expect their coverage to be influenced by demand- and supply-side variables along the electoral cycle. Indeed, from the reader's point of view, as the elections approach, the value she attaches to news about corruption scandals increases, as knowing about misuses of public resources might help to cast her vote knowingly at the elections. ${ }^{9}$ This implies that also the coverage of corruption scandals by the media will possibly increase following the increase in the demand for this kind of news. Moreover, just given the potentially strong effects they might have on the voters' preferences, whether an electoral cycle in their coverage does exist, then there would be a clear incentive for the media to slant it according to their own ideology, trying to affect the electoral results. In particular, if an 'electoral cycle bias' does exist, we should observe that the two newspapers cover more corruption scandals as the election approaches (demand-side effect), emphasizing those scandals involving the political party opposite to the their own ideology, and leaving unaltered, or even reducing, the coverage of those involving politicians closer to their ideology, or with any political connection (supply-side effect).

In order to test for the presence of this 'electoral cycle bias', we estimate the following Least Square Dummy Variable (LSDV) model:

\footnotetext{
${ }^{9}$ Costas-Perèz et al. (2012) analyze the effect of the availability of information about corruption scandals on electoral outcomes using Spanish data, and they find a strong and significant negative effect on the incumbent's vote share after a corruption scandals.
} 


$$
\begin{aligned}
\text { Articles }_{i j t}^{c}=\beta_{0} & +\beta_{1} \text { Rep }_{i}+\beta_{2} \text { Election }_{j t}+\beta_{3} \text { Rep }_{i} * \text { Election }_{j t}+ \\
& +\sum^{m} \beta_{m} \mathbf{X}+\eta_{j}+\theta_{m}+\delta_{d}+\gamma_{y}+\varepsilon_{i j t}
\end{aligned}
$$

where the dependent variable Articles $_{i j t}^{c}$ is defined - according to Puglisi and Snyder (2011) - as the number of articles produced on a specific corruption episode at the date $t$ (a day between October 19th 2002, and April 10th 2014) by the newspaper $i$ (La Repubblica, Il Giornale) about corruption scandals occurred in the region $j$, separately for each possible political orientation of people involved in the scandals $c$ (Left episodes, Right episodes, No-political episodes).

In particular, we regress the number of articles on a constant, a dummy variable $\left(R_{e} p_{i}\right)$ indicating if the newspaper $i$ is La Repubblica, a dummy variable (Election ${ }_{j t}$ ) signaling if the date $t$ is within 14 days before the next electoral round in region $j$, their interaction $\left(\operatorname{Rep}_{i} *\right.$ Election $\left._{j t}\right)$, several time-varying controls, region-fixed effects $\left(\eta_{j}\right)$, month-fixed effects $\left(\theta_{m}\right)$, day-fixed effects $\left(\delta_{d}\right)$ year-fixed effects $\left(\gamma_{y}\right)$ and an error term $\varepsilon_{i j t}$ (with standard errors adjusted for heteroschedasticity and clustered by newspaper within each region). More specifically, $\beta_{1}$ tells us the different number of articles produced per each episode by La Repubblica with respect to Il Giornale in no electoral times. $\beta_{2}$ provides the difference in the number of articles produced per episode by Il Giornale within 14 days from the election with respect to other periods. $\beta_{3}$ represents how much the difference in the number of articles per observation between the two newspapers varies as the election draws near, while $\beta_{2}+\beta_{3}$ how much the number of articles produced per episode by La Repubblica within 14 days from the election differs with respect to other periods. Identification is guaranteed by the exogeneity of the electoral date few days before the elections take place, since the call for elections is a process requiring several months. However, we will also discuss the potential endogeneity of some rounds of elections with respect to corruption news in what follows.

The set of controls $\boldsymbol{X}$ includes variables varying at different lags of time, some possibly with monthly variation, while some others by year. The complete list of controls is in Appendix 
B, together with a brief description and the source of data. Starting from the first group, it is reasonable to assume that the higher is the number of corruption cases already detected, the higher will be the probability that a newspaper will publish news about them. Thus, we control for both the total number of corruption scandals already discovered up to date $t$ in region $j$ and the number of new ones discovered at date $t^{10}$, and these controls are defined separately for each political orientation of the scandal $c$. To take into account how the coverage of corruption scandals by newspaper $i$ at date $t$ is affected by the general coverage of this type of news within the Italian market of newspapers, we control for the number of articles about episodes of corruption in region $j$ produced by $\mathrm{Il}$ Corriere della Sera at the date $t^{11}$, which is also calculated separately for each political orientation of the scandal $c$. In addition, among the first group of controls there are also three variables accounting for the possible heterogeneity in the coverage of corruption scandals linked to the Italian political framework both at regional and national level at date $t$, and possibly interacting with the newspaper $i$ 's ideology. Specifically, we include a dummy indicating if the incumbent governor of region $j$ at date $t$ belongs to the right-wing party, the number of consecutive terms she has been elected and a dummy signaling if the incumbent prime minister at date $t$ belongs to the right-wing party.

As for the group of controls varying only by year, it includes variables possibly affecting both the propensity of the two newspapers to cover news about corruption scandals related to the NHS in the Italian regions and the possibility that new episodes of corruption are discovered, which could eventually lead to more articles. As covering, or even discovering, a corruption scandal might be costly, we add the newspapers' turnover in the year $y-1$ as a control for their financial resources since we assume that higher resources could lead in general to higher coverage. ${ }^{12}$ In order to account for the newspaper' $i$ 's specific interest

${ }^{10}$ We considered as already discovered all those corruption scandals which appear in our sample (considering also Il Corriere della Sera) at least once before the date $t$, while we consider as new all those appearing for the first time at the date $t$.

${ }^{11}$ This number is derived from the Factiva archive through the same procedure described in Section 2 for $L a$ Repubblica and Il Giornale. We use Il Corriere della Sera as reference newspaper for the entire market both because it has one of the highest and most homogeneous diffusion over the Italian territory, and because of its widely recognized centrist ideological stance.

${ }^{12}$ We use the value lagged at $y-1$ to avoid possible endogeneity with the newspaper i's current sales, which 
in the public affairs of the region $j$, which might ultimately affect its propensity to report corruption stories, we use the ratio between the newspaper $i$ 's diffusion within the region $j$ and its national diffusion both at the year $y-1 .^{13}$

Given the number of articles produced at the date $t$ by newspaper $i$ about corruption scandals in the region $j$ being intrinsically connected with both the possibility that new cases arise, and are discovered by the judicial authority, we employ two dummies to control for these sources of heterogeneity. One indicates whether the public health expenditure per capita in region $j$ is above the national average in the year $y$, assuming that where there is more money there is also more room for corruption, and the other dummy takes value 1 if the regional public expenditure in security in region $j$ is above the national average in the year $y$, as more resources for investigating on corruption are likely to lead to discover more episodes.

\section{Results}

The estimates of Equation 1 are presented in Table 2. For each political orientations of corruption scandals we run two different specifications, one without any control, and one including all of them. Given the use of interaction terms in our regressions, in order to make easier the general interpretation of the results we calculate in Table 3 the marginal effects of the main explanatory variables on the expected daily number of articles produced about corruption scandals, by political orientation of the scandals.

Starting the analysis from the articles about corruption scandals involving left-wing politicians, and considering the complete specification of Equation 1 (column (2) of Table 2), Il Giornale produces in general 0.21 articles more in the 14 days before the election than in other periods, corresponding to 1.70 daily articles against 1.50 (column (1) of Table 3). Although such difference is only weakly significant (at 10\%), it accounts for $38 \%$ of $\mathrm{Il}$ Giornale's standard deviation in the number of articles produced per observation about might be influenced by the coverage of corruption scandals.

${ }^{13}$ We use the value lagged at $y$ - 1 in order avoid feasible endogeneity with the newspaper $i$ 's current relative diffusion in region $j$, which might be influenced by the its coverage of corruption scandals. 
left episodes of corruption (first column of the bottom part of Table 1). Concerning $L a$ Repubblica, it does not show any significant difference in its coverage of this kind of news with respect to $\mathrm{Il}$ Giornale neither during electoral times, nor in other periods, even if it does actually produce less articles about left episodes both in no electoral periods (1.07 against 1.50 produced by $I l$ Giornale) and within 14 days from the election (1.29 against 1.70 produced by Il Giornale). Indeed, although also La Repubblica seems to experience an increase in the daily number of articles about left episodes of corruption when elections are approaching (around 0.22 , from 1.07 to 1.29 ), this difference is not statistically different from zero. In addition, as also Il Giornale increases the number of articles about left episodes of corruption in electoral times by almost the same degree, the general difference between the two newspapers does not vary when elections are approaching but remains almost stable as the coefficient for Rep $\times$ Election shows (column (2) of Table 2).

As for the articles about corruption scandals involving right-wing politicians (column (4) of Table 2, and column (2) of Table 3), Il Giornale reduces in a significant way during election times the daily number of these articles of about 0.36 pieces, from an already low mean in no electoral periods (0.42 and not significantly different from zero), representing $55 \%$ of the standard deviation in the number of articles about right episodes of corruption per observation for this newspaper (second column of the bottom part of Table 1). Like for the left episodes of corruption, also for the right ones the difference between the number of daily articles produced by La Repubblica and Il Giornale is not statistically different from zero, neither in no electoral periods, nor within 14 days from the elections, even if its size is definitively greater than for the left episodes, as showed in column (4) of Table 2 (1.04 articles within no electoral periods and 1.45 articles during electoral times). Moreover also in this case the differences between the number of articles produced by La Repubblica within 14 days before the elections is not statistically different from the same number in the other periods, being the former just slightly bigger than the latter (1.51 against 1.46 in no electoral times). Differently from the previous case, now the difference in how the daily number of articles varies between the two newspapers as the election is approaching is positive and strongly significant: as the election gets closer, the difference in the daily 
number of articles about right episodes of corruption between La Repubblica and Il Giornale significantly changes by increasing of about 0.41 articles (from 1.04 to 1.45). In particular, such increase is mainly driven by the reduction in the number of articles by $\mathrm{Il}$ Giornale rather than to an increase in the coverage of this type of news by La Repubblica, that we found to be very small (1.46 against 1.51).

Finally, with respect to corruption scandals not involving politicians, also in this case $I l$ Giornale reduces its daily coverage by about 1 article as the election gets closer (column (6) of Table 2), moving from 1.62 articles before the electoral period to 0.63 in the electoral times. The impact is statistically significant, stronger than for the right episodes, corresponding to $150 \%$ of the standard deviation in the daily number of articles about no political episodes of corruption for this newspaper (column (3) of the bottom part of Table 1). As for the other types of corruption scandals, also with respect to those not involving politicians, La Repubblica does not show significant differences in the daily number of articles about these scandals with respect to $\mathrm{Il}$ Giornale, neither in no electoral periods $(0.52$ articles less than Il Giornale), nor in electoral times (0.66 articles more than Il Giornale). Still consistently with the other types of corruption scandals, the daily number of articles produced by La Repubblica within 14 days before the election is not statistically different from the same number in other periods (1.10 against 1.29 in election times). Furthermore, as for the right episodes of corruption, the difference in how the daily number of articles varies between the two newspapers as the elections approach is positive and strongly significant, and even greater than for the right episodes of corruption, signaling that as the elections draw near the difference in the daily number of articles about no political episodes of corruption between La Repubblica and Il Giornale significantly changes by increasing of about 1.18 articles (0.52 articles less in no electoral periods against 0.66 articles more in electoral times), and just like the right episodes of corruption this increase is essentially driven by the reduction in the number of articles about scandals not involving politicians by Il Giornale rather than to an increase in the coverage of this type of news by La Repubblica. To sum up, our results support the existence of a partisan 'electoral cycle bias' in the coverage of news about corruption scandals by Il Giornale, whose sign depends on the 
interaction between its own ideology and the political orientation of the scandals. As the elections get closer, it increases significantly the daily number of articles about episodes involving left-wing politicians, whereas it diminishes significantly the number of those about right-wing politicians and those not involving politicians. On the contrary, such electoral cycle in the coverage of corruption scandals is not detectable for La Repubblica, regardless of the political orientation of the individuals involved in the scandals. Indeed, although as the elections draw near it increases the daily production of articles about corruption scandals of whatever kind, such increases are never statistically different from zero. Moreover, we do not find evidence supporting the existence of an ideological bias affecting the coverage of corruption scandals by La Repubblica. Despite this newspaper produces in general less articles about left episodes of corruption ( 0.43 articles less in no electoral periods and 0.41 in election times) and more articles about right episodes than Il Giornale (1.06 articles more in no electoral periods and 1.46 in election times), these differences are never significantly different from zero. The absence of both an ideological bias and an electoral cycle bias in the coverage of corruption scandals by La Repubblica might be related to a lower degree of ideological polarization with respect to Il Giornale and (or) to the higher average number of readers, which ultimately demand to cover more corruption scandals, independently from the timing and the political orientation of the scandals, in order to satisfy their interest for this kind of news.

\section{Robustness checks}

In this section we check the robustness of our results with respect to a different specification of the regression model, to the potential endogeneity of some rounds of elections, and to different definitions of the time frame before the next electoral round.

\subsection{A different specification}

By construction, our dependent variable can take up only strictly positive and integer values. For this reason, as a first robustness test, we properly consider the three dependent 
variables as count variables and we re-run the models employing the same explanatory variables and controls included in Equation 1, but using now a Negative Binomial specification. We prefer the Negative Binomial model to a Poisson model since our dependent variables are affected by over dispersion (Figure 3): regardless of the political orientation, the average number of articles per observation is always around three times greater than its variance. Indeed, as clear from Figure 4, the Negative Binomial distribution fits definitively better than a Poisson the actual distribution, for all the possible political orientation of the scandals.
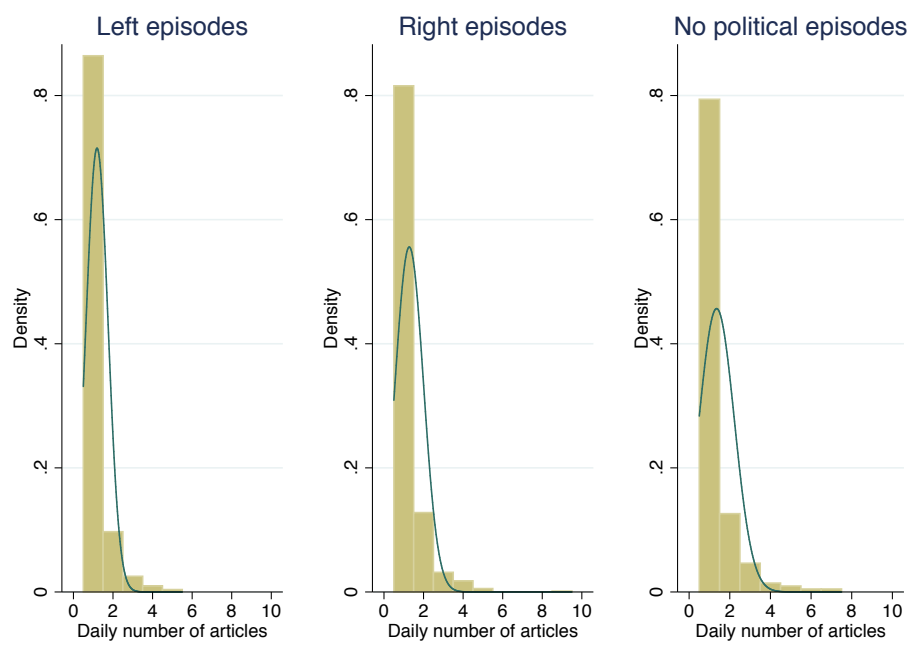

Figure 3: Distribution of the daily number of articles about corruption scandals.

Note: The figure shows the distribution of the daily number of articles about of the cases of corruption scandals in the Italian regions related to the NHS produced from 2002 to 2014, disentangled by political orientation of the individuals involved in the scandals. The green line in each graph represents the density of a normal distribution calculated with respect to our estimation samples.

The results of this test are presented in Table 4, where reported coefficients represents Incidence Rate Ratios (IRR), while the marginal effects on the number of articles per observation is provided in Table $5 .{ }^{14}$

Both the estimates and the expected number of articles per observation are very much

${ }^{14}$ Each incidence rate is computed considering the average number of pages included in each newspaper in the period 2002-2014. Additional details about this variable are provided in the Appendix B. 

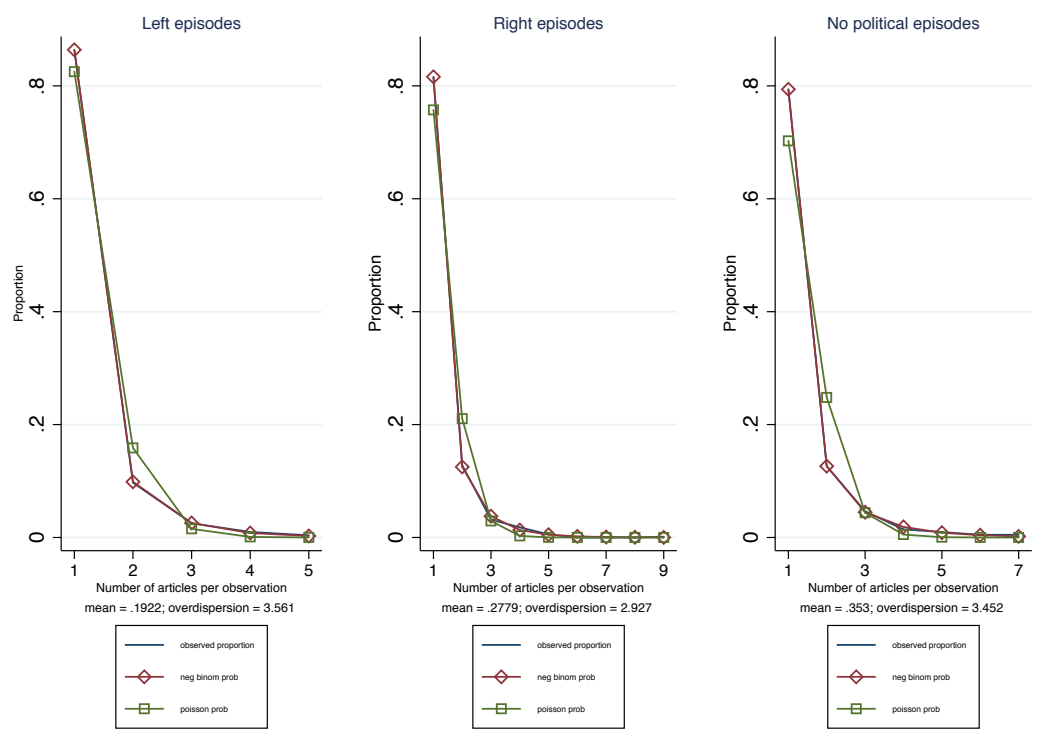

Figure 4: Comparison between different distributions of the number of articles about corruption scandals.

Note: The figure shows the actual distribution of the observations within the estimation sample for each political orientation of the corruption scandals (blue lines), against both a Poisson (green lines) and a Negative binomial distribution (red lines).

consistent with our baseline specification. Il Giornale produces $21 \%$ more articles about left episodes of corruption during election times than in other periods (2.21 against 2.68), and it reduces those about no political episodes by about 50\% (from 2.08 to 1.03), but differently from the LSDV model, it does not significantly vary the number of articles about scandals involving right-wing politicians (from 0.89 to 0.82 ). As in the main analysis, regardless of the political orientation of the corruption scandals, La Repubblica does not show any significant variation in its coverage of such scandals, neither as the elections draw near, nor with respect to Il Giornale in electoral and no electoral periods, thus confirming its general low degree of ideological bias. Nonetheless, still similar to the LSDV models, $L a$ Repubblica increases significantly in election times its difference in the number of articles about right and non political episodes of corruption with respect to Il Giornale (of about $20 \%$ and $123 \%$ respectively), but again the difference with its own production in no electoral periods is not significant, signaling the absence of an electoral cycle bias for this newspaper. 


\subsection{A different sample}

The discovery of a corruption scandal, and its extensive coverage by newspapers, could lead the incumbent regional governor to resign; eventually, this will imply an anticipation of the electoral round with respect to its normal schedule. Such reverse effect of the coverage of the scandals by newspapers on the electoral cycle might induce endogeneity in our estimates. In particular, we could end up with some observations (i.e., those between the date of the last electoral round and the date of the governor's resignation) whose distance from the election does not reflect the normal conclusion of a legislation, being anticipated exactly because of the corruption scandal. According to Italian legislation, which requires call for new elections to take several months, the very short time frame we consider should exclude any effects of this kind. Yet, we checked for cases of corruption ended up with the resignation of elected governors. There are only two such cases in our sample: one refers to the left-wing politician Ottaviano del Turco, who was elected governor of Regione Abruzzo on April 4th 2005 and resigned on July 17th 2008 (new elections took place December 14th-15th 2008); the second one refers to the right-wing politician Roberto Formigoni, who was elected governor of Regione Lombardia on March 29th 2010 and resigned on October 26th 2012 (new elections took place February 24th-25th 2013).

In order to test the robustness of our results with respect to this issue we re-run Equation 1 , excluding from the sample all the observations for these two regions, recorded between the pairs of dates described above. These new estimates are presented in Table 6 while the marginal effects are showed in Table 7 . Results are largely confirmed, both in terms of magnitude and significance. The only difference concerns the variation in the coverage by Il Giornale of corruption scandals involving right-wing politicians within 14 days from the election which is still negative but no longer significant. This result is hardly surprising and shows the importance of the case involving the right wing politician Roberto Formigoni for Il Giornale. Differently from other governors, Mr. Formigoni is a key figure also in the national politics (he has recently been a member of the Italian Senate) and shared significant linkages with Mr. Berlusconi. 


\subsection{Different definitions of the distance from elections}

We finally test the robustness of our results with respect to the definition of the time interval to elections. Specifically, instead of considering the 14 days frame, we use as alternative time intervals 0-7 days ( 1 week), 0-28 days (4 weeks), 0-42 days (6 weeks) and 0-56 days ( 8 weeks).

The results of this test are showed in Table 8 and 9. The use of different time periods for defining the dummy Election does not affect our main results, since also these new estimates are very similar in sign, magnitude and significance to those showed in Table 2. Moreover, looking at the size of the coefficients, they are decreasing in the length of the interval considered ${ }^{15}$, a result which brings further support to the existence of an 'electoral cycle bias' in the coverage of news about corruption scandals.

\section{Conclusions}

It is hardly surprising that, in a democracy, politicians have strong incentives to use policy tools to influence voters' preferences when elections get near. But an issue that the political budget cycle literature as only marginally discussed is the role of media in this strategy, which is driven by both users' preferences and the ideological stance of the media. The literature on the political economy of mass media has discussed so far a number of dimensions on which media can operate an ideological selection: the issue to be covered, the specific aspects of the issue to highlight or exclude, how facts are presented and discussed and which sources to rely on. In this work we add to the literature by investigating the existence of an ideological bias in the coverage of news about corruption induced by the electoral cycle. Our empirical analysis is based on an original database containing all the articles produced by two of the most important Italian newspapers which are also charac-

${ }^{15}$ The absence of news from Il Giornale about right episodes of corruption within 7 days from the elections (which does not allow us to estimate the coefficient for Rep $\times$ Election) might be interpreted as an evidence in favor of the stronger effect of the electoral cycle on Il Giornale's coverage of right episodes of corruption as the distance from the elections comes closer. The "electoral cycle bias" is so strong that this newspaper prefer to avoid completely to publish articles about this kind of scandals as the elections are very close in order to minimize possible negative effects on the right-wing politicians running for the election. 
terized by a clear ideological stance ( La Repubblica and Il Giornale, left and right-oriented respectively) about corruption scandals related to public health care in the Italian regions during the period 2002-2014. News about corruption in health care have an high value for regional elections in Italy, since health spending makes up the largest share of regional budgets.

Our results supports the existence of a partisan 'electoral cycle bias' in the coverage of news about corruption scandals by $I l$ Giornale only. As the elections get closer, this newspaper increases significantly the daily number of articles about episodes involving leftwing politicians, whereas it diminishes significantly the number of those about right-wing politicians and those not involving politicians. On the contrary, we do not find evidence of an 'electoral cycle bias' in the coverage of corruption scandals by La Repubblica. Moreover, despite La Repubblica produces in general less articles about left episodes of corruption and more articles about right episodes than Il Giornale, these differences are never significantly different from zero. The absence of both an ideological bias and an electoral cycle bias in the coverage of corruption scandals by La Repubblica might be related to a lower degree of ideological polarization with respect to $\mathrm{Il}$ Giornale and (or) to the higher average number of readers, which ultimately demand to cover more corruption scandals, independently from the timing and the political orientation of the scandals, in order to satisfy their interest for this kind of news. All of which might be related to the degree of competitiveness of the Italian market for news, which is lower than what observed for instance in the US.

Unfortunately, due to the reduced number of observations available, we are not able here to properly identify the possible impact on the electoral outcomes of the bias detected for Il Giornale. Nonetheless, anecdotal evidence on the two cases ended up with governors resignation shows that corruption news are particularly salient for voters. In Lombardia, the vote share for the right-wing coalition declined from 56.11 per cent in 2010 - before the scandal involving Mr. Formigoni - to 42.81 per cent in 2013. The right-wing coalition still had the majority, but the new governor was expressed by a different party in the coalition. Moreover, the vote share of the party supporting Mr. Formigoni halved, from 31.79 percent in 2013 to 16 percent in 2010. In Abruzzo, the winning left-wing coalition in 2005 - before 
the scandal involving Mr. Del Turco - lost the majority in the 2008 elections, with the vote share declining from 58.24 per cent to 42.67 percent.

Finally, the results produced in this study might have at least two important implications. First, from a positive standpoint, since corruption is - by definition - unobservable, a biased reporting of corruption news implies biased perceptions of corruption in a given country. This bias might help explain findings of corruption cycles in Sidorkin and Vorobyev (2017), and it induces some cautions in the use of corruption measures (like the standard Corruption Perception Index produced by Transparency International, widely used in economics research), since they might be influenced by unexpected factors like the size of a readership, or the closeness to elections. This is also true for the specific cases of corruption we are considering here, which relates to a sector quite vulnerable to corruption all over the world (see, e.g., Vian (2008)). Second, from a normative standpoint, since corruption news are salient for voters and can influence electoral outcomes (see, e.g., Costas-Perèz et al. (2012)), our findings support the view of full transparency on the linkages between media owners and political parties - if not a clear separation between the two - to make the democratic mechanism to work better (Corneo, 2006). 


\begin{tabular}{lcccccc}
\hline \hline & $(1)$ & $(2)$ & $(3)$ & $(4)$ & $(5)$ & $(6)$ \\
\hline \multirow{4}{*}{ Rep } & Left episodes & Left episodes & Right episodes & Right episodes & NP episodes & NP episodes \\
& $0.141^{* * *}$ & -0.428 & 0.016 & 1.043 & -0.027 & -0.520 \\
Election & $(0.045)$ & $(0.679)$ & $(0.067)$ & $(0.994)$ & $(0.0823)$ & $(0.837)$ \\
& $0.212^{*}$ & $0.207^{*}$ & $0.317^{* * *}$ & $-0.361^{* *}$ & $-0.263^{* * *}$ & $-0.989^{* * *}$ \\
RepXElection & $(0.102)$ & $(0.116)$ & $(0.061)$ & $(0.138)$ & $(0.070)$ & $(0.267)$ \\
& 0.0179 & 0.0160 & $-0.182^{* *}$ & $0.410^{* * *}$ & $0.693^{* * *}$ & $1.180^{* * *}$ \\
& $(0.206)$ & $(0.195)$ & $(0.067)$ & $(0.074)$ & $(0.184)$ & $(0.281)$ \\
\hline \multirow{2}{*}{ Controls } & No & Yes & No & Yes & No & Yes \\
Year dummies & No & Yes & No & Yes & No & Yes \\
Month dummies & No & Yes & No & Yes & No & Yes \\
Day dummies & No & Yes & No & Yes & No & Yes \\
\hline Observations & 339 & 339 & 383 & 383 & 345 & 345 \\
$R^{2}$ & 0.019 & 0.329 & 0.002 & 0.342 & 0.014 & 0.270 \\
\hline \hline
\end{tabular}

Table 2: LSDV estimation results

Dependent variables: Daily number of articles about corruption scandals involving left-wing politicians (columns (1) and (2)), right-wing politicians (columns (3) and (4)) or any political party (columns (5) and (6)). All the estimates are obtained through the Least Square Dummy Variable regression model presented in Equation 1. Column (2) controls for the cumulative number of corruption scandals involving left-wing politicians already discovered in the region $j$ up to the date $t$, the number of new scandals discovered at date $t$, and the daily number of articles about left episodes of corruption in the NHS in the region $j$ produced by Il Corriere della Sera at date $t$. Column (4) controls for the cumulative number of corruption scandals involving right-wing politicians already discovered in the region $j$ up to the date $t$, the number of new scandals discovered at date $t$, and the daily number of articles about right episodes of corruption in the NHS in the region $j$ produced by Il Corriere della Sera at date $t$. Column (6) controls for the cumulative number of corruption scandals with any political connection already discovered in the region $j$ up to the date $t$, the number of new scandals discovered at date $t$, and the daily number of articles about no political episodes of corruption in the NHS in the region $j$ produced by Il Corriere della Sera at date $t$. Columns (2),(4) and (6) also control if the incumbent governor in region $j$ at time $t$ belongs to the right-wing party, for the number of consecutive terms she has been elected, if the incumbent prime minister at the date $t$ belongs to the right-wing party, for the newspapers' turnover at the year $y$-1, for the ratio at the year $y$ - 1 between the newspapers' diffusion within region $j$ and at national level, if the public health expenditure per capita in region $j$ at the year $y$ is above the national average and if the public expenditure in security in region $j$ at the year $y$ is above the national average. Moreover they all contain dummies to account for region-fixed effects, month-fixed effects, day-fixed effects and year-fixed effects. The bottom part of the table reports the $R^{2}$ of each specification. All the standard errors are robust to heteroschedasticity and clustered by newspaper for each region. $*, * *, * * *$ indicate statistical significance at $10 \%, 5 \%$ and $1 \%$ level respectively. 


\begin{tabular}{lccc}
\hline \hline & $(1)$ & $(2)$ & $(3)$ \\
& Left episodes & Right episodes & NP episodes \\
La RepubblicaXNo Election & $1.07^{* * *}$ & $1.46^{* * *}$ & $1.10^{* * *}$ \\
La RepubblicaXElection & $1.29^{* * *}$ & $1.51^{* * *}$ & $1.29^{* *}$ \\
Il GiornaleXNo Election & $1.50^{* * *}$ & 0.42 & $1.62^{* *}$ \\
Il GiornaleXElection & $1.70^{* * *}$ & 0.05 & 0.63 \\
\hline & & & \\
La RepubblicaXElection - La RepubblicaXNo Election & 0.22 & 0.05 & 0.19 \\
Il GiornaleXElection - Il GiornaleXNo Election & $0.21^{*}$ & $-0.36^{* *}$ & $-0.99^{* * *}$ \\
La RepubblicaXNoElection - Il GiornaleXNoElection & -0.43 & 1.04 & -0.52 \\
La RepubblicaXElection - Il GiornaleXElection & -0.41 & 1.45 & 0.66 \\
\hline \hline
\end{tabular}

Table 3: Marginal effects on the expected number of daily articles about corruption scandals.

Note: The upper part of the table shows the marginal effect on the expected daily number of articles about corruption scandals involving left-wing politicians (columns (1)) or right-wing politicians (columns (2)). All the values rely on the coefficients presented in Table 2, and in particular to the most completed specifications (columns (2) and (4) of Table 2). The bottom part of the table provides the differences in the number of articles produced by La Repubblica in no electoral periods and electoral times, by Il Giornale in no electoral periods and electoral periods, by the two newspapers in no electoral times and by the two newspapers as the elections approach. *, **, *** indicate statistical significance at $10 \%, 5 \%$ and $1 \%$ level respectively. 


\begin{tabular}{lccc}
\hline \hline & $(1)$ & $(2)$ & $(3)$ \\
\hline \multirow{4}{*}{ La Rep } & Left episodes & Right episodes & No-political episodes \\
& 0.465 & 1.523 & 0.518 \\
Election & {$[0.224]$} & {$[1.149]$} & {$[0.284]$} \\
& $1.212^{* *}$ & 0.919 & $0.495^{* * *}$ \\
La RepXElection & {$[0.103]$} & {$[0.094]$} & {$[0.083]$} \\
\hline Controls & 1.000 & $1.203^{* * *}$ & $2.233^{* * *}$ \\
Year dummies & Yes & Yes & Yes \\
Month dummies & Yes & Yes & Yes \\
Day dummies & Yes & Yes & Yes \\
Regional dummies & Yes & Yes & Yes \\
\hline Observations & 339 & Yes & Yes \\
\hline \hline
\end{tabular}

Table 4: Negative Binomial estimation results.

Dependent variables: Daily number of articles about corruption scandals involving left-wing politicians (columns (1)), right-wing politicians (columns (2)) or any political party (columns (3)). All the estimates are obtained through a Negative Binomial regression model and they are all presented as Incidence Rate Ratios (IRR). Column (1) controls for the cumulative number of corruption scandals involving left-wing politicians already discovered in the region $j$ up to the date $t$, the number of new scandals discovered at date $t$, and the daily number of articles about left episodes of corruption in the NHS in the region $j$ produced by Il Corriere della Sera at date $t$. Column (2) controls for the cumulative number of corruption scandals involving right-wing politicians already discovered in the region $j$ up to the date $t$, the number of new scandals discovered at date $t$, and the daily number of articles about right episodes of corruption in the NHS in the region $j$ produced by $\mathrm{Il}$ Corriere della Sera at date $t$. Column (3) controls for the cumulative number of corruption scandals with any political connection already discovered in the region $j$ up to the date $t$, the number of new scandals discovered at date $t$, and the daily number of articles about no political episodes of corruption in the NHS in the region $j$ produced by Il Corriere della Sera at date $t$. Columns (1), (2) and (3) also control if the incumbent governor in region $j$ at time $t$ belongs to the right-wing party, for the number of consecutive terms she has been elected, if the incumbent prime minister at the date $t$ belongs to the right-wing party, for the newspapers' turnover at the year $y$-1, for the ratio at the year $y$-1 between the newspapers' diffusion within region $j$ and at national level, if the public health expenditure per capita in region $j$ at the year $y$ is above the national average and if the public expenditure in security in region $j$ at the year $y$ is above the national average. Moreover, they all contain dummies to account for region-fixed effects, year-fixed effects, month-fixed effects, day-fixed effects. We use as exposure variable for each newspaper the average number of pages it includes along the period 2002-2014, corresponding to 60 for La Repubblica and 40 for Il Giornale. All the standard errors are robust to heteroschedasticity and clustered by newspaper for each region. ${ }^{*}, * *, * * *$ indicate statistical significance at $10 \%, 5 \%$ and $1 \%$ level respectively. 


\begin{tabular}{lccc}
\hline \hline & $(1)$ & $(2)$ & $(3)$ \\
& Left episodes & Right episodes & No political episodes \\
La RepubblicaXNo Election & $1.03^{* * *}$ & $1.35^{* * *}$ & $1.08^{* * *}$ \\
La RepubblicaXElection & $1.25^{* * *}$ & $1.49^{* * *}$ & $1.19^{* * *}$ \\
Il GiornaleXNo Election & $2.21^{* * *}$ & $0.89^{* *}$ & $2.08^{* *}$ \\
Il GiornaleXElection & $2.68^{* * *}$ & $0.82^{* *}$ & $1.03^{* *}$ \\
& & & \\
\hline La RepubblicaXElection - La RepubblicaXNo Election & 0.22 & 0.14 & 0.11 \\
Il GiornaleXElection - Il GiornaleXNo Election & $0.47^{* * *}$ & -0.07 & $-1.05^{* *}$ \\
La RepubblicaXNoElection - Il GiornaleXNoElection & 1.18 & 0.46 & -1 \\
La RepubblicaXElection - Il GiornaleXElection & -1.43 & 0.68 & 0.16 \\
\hline \hline
\end{tabular}

Table 5: Marginal effects on the expected number of daily articles about corruption scandals - Negative Binomial.

Note: The table shows the marginal effect on the expected daily number of articles about corruption scandals involving left-wing politicians (columns (1)), right-wing politicians (columns (2)) or any political party (columns (3)). All the values rely on the coefficients presented in Table 4 . The bottom part of the table provides the differences in the number of articles produced by La Repubblica in no electoral periods and electoral times, by Il Giornale in no electoral periods and electoral periods, by the two newspapers in no electoral times and by the two newspapers as the elections approach. $*{ }^{* *}, * * *$ indicate statistical significance at $10 \%, 5 \%$ and $1 \%$ level respectively. 


\begin{tabular}{lccc}
\hline \hline & $(1)$ & $(2)$ & $(3)$ \\
\hline \multirow{3}{*}{ Rep } & Left episodes & Right episodes & No-political episodes \\
& -0.104 & 0.295 & -0.518 \\
Election & {$[0.526]$} & {$[1.398]$} & {$[0.835]$} \\
& $0.234^{* *}$ & -0.0861 & $-0.993^{* * *}$ \\
RepXElection & {$[0.105]$} & {$[0.154]$} & {$[0.264]$} \\
& 0.0460 & $0.270^{* * *}$ & $1.185^{* * *}$ \\
& {$[0.136]$} & {$[0.0777]$} & {$[0.287]$} \\
\hline \multirow{2}{*}{ Controls } & Yes & Yes & Yes \\
Year dummies & Yes & Yes & Yes \\
Month dummies & Yes & Yes & Yes \\
Day dummies & Yes & Yes & Yes \\
\hline Observations & 334 & 308 & 342 \\
$R^{2}$ & 0.277 & 0.349 & 0.269 \\
\hline \hline
\end{tabular}

Table 6: LSDV estimation results - different estimation sample.

Dependent variables: Daily number of articles about corruption scandals involving left-wing politicians (columns (1)), right-wing politicians (columns (2)) or any political party (columns (3)). All the estimates are obtained through the Least Square Dummy Variable regression model presented in Equation 1. Column (1) controls for the cumulative number of corruption scandals involving left-wing politicians already discovered in the region $j$ up to the date $t$, the number of new scandals discovered at date $t$, and the daily number of articles about left episodes of corruption in the NHS in the region $j$ produced by Il Corriere della Sera at date $t$. Column (2) controls for the cumulative number of corruption scandals involving right-wing politicians already discovered in the region $j$ up to the date $t$, the number of new scandals discovered at date $t$, and the daily number of articles about right episodes of corruption in the NHS in the region $j$ produced by $I l$ Corriere della Sera at date $t$. Column (3) controls for the cumulative number of corruption scandals with any political connection already discovered in the region $j$ up to the date $t$, the number of new scandals discovered at date $t$, and the daily number of articles about no political episodes of corruption in the NHS in the region $j$ produced by $I l$ Corriere della Sera at date $t$. All the columns also control if the incumbent governor in region $j$ at time $t$ belongs to the rightwing party, for the number of consecutive terms she has been elected, if the incumbent prime minister at the date $t$ belongs to the right-wing party, for the newspapers' turnover at the year $y$ - 1 , for the ratio at the year $y$ - 1 between the newspapers' diffusion within region $j$ and at national level, if the public health expenditure per capita in region $j$ at the year $y$ is above the national average and if the public expenditure in security in region $j$ at the year $y$ is above the national average. Moreover they all contain dummies to account for region-fixed effects, year-fixed effects, month-fixed effects, day-fixed effects. The bottom part of the table reports the $R^{2}$ of each specification. All the standard errors are robust to heteroschedasticity and clustered by newspaper for each region. *,**,*** indicate statistical significance at $10 \%, 5 \%$ and $1 \%$ level respectively. 


\begin{tabular}{lccc}
\hline \hline & $(1)$ & $(2)$ & $(3)$ \\
\hline & Left episodes & Right episodes & No political episodes \\
La RepubblicaXNo Election & $1.13^{* * *}$ & $1.23^{* * *}$ & $1.11^{* * *}$ \\
La RepubblicaXElection & $1.40^{* * *}$ & $1.41^{* * *}$ & $1.30^{* *}$ \\
Il GiornaleXNo Election & $1.23^{* * *}$ & 0.93 & $1.63^{* *}$ \\
Il GiornaleXElection & $1.47^{* * *}$ & 0.85 & 0.63 \\
\hline & & & 0.19 \\
La RepubblicaXElection - La RepubblicaXNo Election & 0.27 & 0.18 & $-1^{* * *}$ \\
Il GiornaleXElection - Il GiornaleXNo Election & $0.24^{* *}$ & -0.08 & 0.52 \\
La RepubblicaXNoElection - Il GiornaleXNoElection & -0.10 & 0.30 & 0.67 \\
La RepubblicaXElection - Il GiornaleXElection & -0.07 & 0.56 & \\
\hline \hline
\end{tabular}

Table 7: Marginal effects on the expected number of daily articles about corruption scandals - different estimation sample.

Note: The table shows the marginal effect on the expected daily number of articles about corruption scandals involving left-wing politicians (columns (1)), right-wing politicians (columns (2)) or any political party (columns (3)). All the values rely on the coefficients presented in Table 6. The bottom part of the table provides the differences in the number of articles produced by La Repubblica in no electoral periods and electoral times, by Il Giornale in no electoral periods and electoral periods, by the two newspapers in no electoral times and by the two newspapers as the elections approach. $*, * *, * *$ indicate statistical significance at $10 \%, 5 \%$ and $1 \%$ level respectively. 


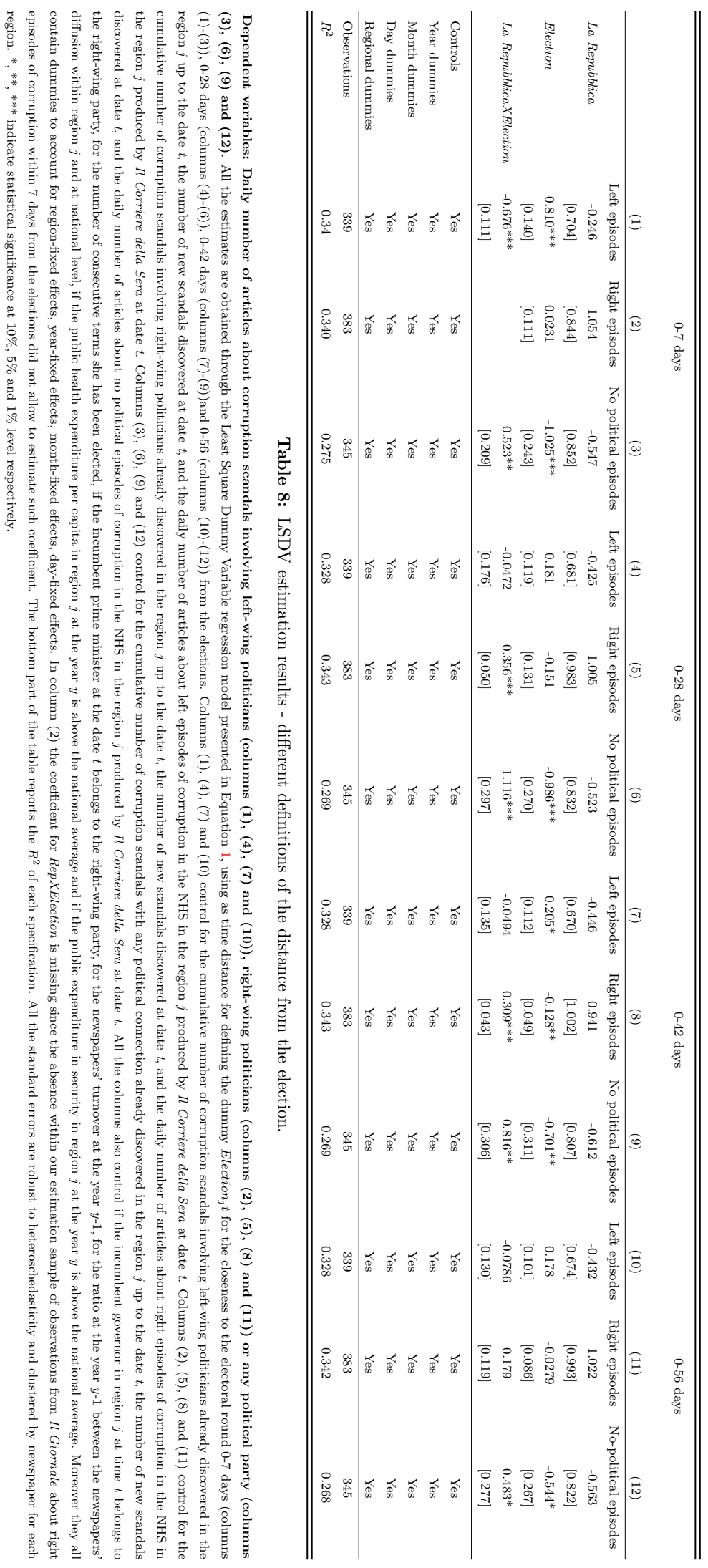




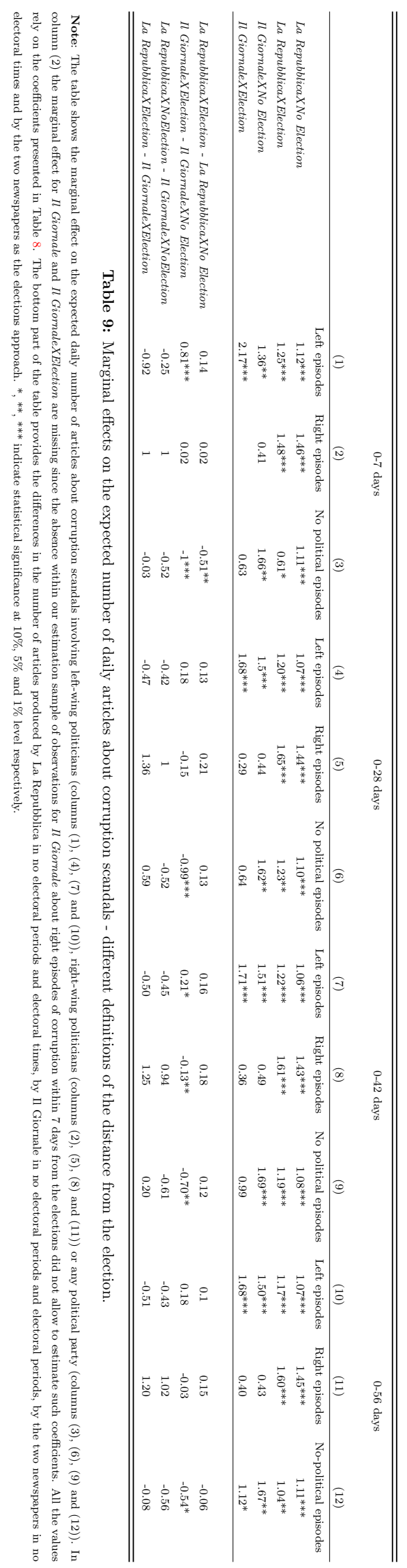




\section{References}

Akhmedov, A. and E. Zhuravskaya (2004). Opportunistic political cycles: Test in a young democracy setting. Quarterly Journal of Economics 119(4), 1301-1338.

Alaoui, L. and F. Germano (2012). Time scarcity and the market for news. UPF Working Paper (1348).

Alesina, A. (1987). Macroeconomic policy in a two-party system as a repeated game. Quarterly Journal of Economics 102(4), 651-678.

Alesina, A. (1988). Macroeconomics and politics. NBER Macroeconomics Annual 1988 3, $13-62$

Alesina, A., G. A. Cohen, and N. Roubini (1997). Political Cycles and the Macroeconomy. MIT Press.

Baron, D. (2006). Persistent media bias. Journal of Public Economics 90(1/2), 1-36.

Berlemann, M. and G. Markwardt (2006). Variable rational partisan cycles and electoral uncertainty. European Journal of Political Economy 22(4), 874-886.

Brender, A. and A. Drazen (2006). Political budget cycles in new versus established democracies. Journal of Monetary Economics 52(7), 1271-1295.

Brender, A. and A. Drazen (2008). How do budget deficits and economic growth affect re-election prospects? evidence from a large panel of countries. American Economic Review 98(5), 2203-2220.

Chan, J. and W. Suen (2008). A spatial theory of news consumption and electoral competition. Review of Economic Studies 75(3), 699-728.

Corneo, G. (2006). Media capture in a democracy: The role of wealth concentration. Journal of Public Economics 90(1-2), 37-58. 
Costas-Perèz, E., A. Solè-Ollè, and P. Sorribas-Navarro (2012). Corruption scandals, voter information, and accountability. European Journal of Political Economy 28(4), 469-484.

De Haan, J. (2013). Democracy, elections and government budget deficits. German Economic Review 15(1), 131-142.

Di Tella, R. and I. Franceschelli (2011). Government advertising and media coverage of corruption scandals. American Economic Journal: Applied Economics 3(4), 119-151.

Di Tella, R. and R. MacCulloch (2005). Partisan social happiness. Review of Economic Studies 72(2), 367-393.

Drazen, A. (2000). The political business cycle after 25 years. NBER Macroeconomics Annual 2000315.

Drazen, A. and M. Eslava (2010). Electoral manipulation via voter-friendly spending: Theory and evidence. Journal of Development Economics 92(1), 39-52.

Dubois, E. (2016). Political business cycles 40 years after nordhaus. Public Choice 166(1/2), 235-259.

Duggan, J. and C. Martinelli (2011). A spatial theory of media slant and voter choice. Review of Economic Studies 78(2), 640-666.

Entman, R. E. (2012). Scandal and Silence: Media Responses to Presidential Misconduct. Polity Press.

Faye, M. and P. Niehaus (2012). Political aid cycles. American Economic Review 102(7), $3516-3530$.

Francese, M., M. Piacenza, M. Romanelli, and G. Turati (2014). Understanding inappropriateness in health spending: The role of regional policies and institutions in caesarean deliveries. Regional Science and Urban Economics 49, 262-277. 
Gentzkow, M., E. L. Glaeser, and C. Goldin (2006). The Rise of the Fourth Estate: How Newspapers Became Informative and Why It Mattered, pp. 187-230. University of Chicago Press.

Gentzkow, M. and J. M. Shapiro (2006). Media bias and reputation. Journal of Political Economy 114(2), 280-316.

Gentzkow, M. and J. M. Shapiro (2010). What drives media slant? evidence from u.s. daily newspapers. Econometrica 78(1), 35-71.

Gratton, G., R. Holden, and A. Kolotilin (2017). When to drop a bombshell. Review of Economic Studies Forthcoming.

Hassett, K. A. and J. R. Lott. (2014). Is newspaper coverage of economic events politically biased? Public Choice 160(1), 65-108.

Heckelman, J. C. (2001). Partisan business cycles under variable election dates. Journal of Macroeconomics 23(2), 261-275.

Hibbs, D. A. (1977). Political parties and macroeconomic policy. American Political Science Review 71 (4), 1467-1487.

Ho, B. and P. Liu (2015). Herd journalism: Investment in novelty and popularity in markets for news. Information Economics and Policy 31, 33-46.

Klomp, J. and J. De Haan (2013). Conditional election and partisan cycles in government support to the agricultural sector: An empirical analysis. American Journal of Agricultural Economics 95(4), 793-818.

Larcinese, V., R. Puglisi, and J. M. Snyder (2011). Partisan bias in economic news: Evidence on the agenda-setting behavior of u.s. newspapers. Journal of Public Economics 95(9/10), 1178-1189.

McChesney, R. (2015). Rich media, poor democracy: communication politics in dubious times. The New Press. 
Mullainathan, S. and A. Shleifer (2005). The market for news. American Economic Review 95(4), 1031-1053.

Nordhaus, W. D. (1975). The political business cycle. Review of Economic Studies 42(2), 169-190.

Piacenza, M. and G. Turati (2014). Does fiscal discipline towards sub-national governments affect citizens' well-being? evidence on health. Health Economics 23(2), 199-224.

Potrafke, N. (2010). The growth of public health expenditures in oecd countries: Do government ideology and electoral motives matter? Journal of Health Economics 29(6), 797-810.

Prat, A. and D. Strömberg (2013). The political economy of mass media. Advances in Economics and Econometrics: Theory and Applications, Proceedings of the Tenth World Congress of the Econometric Society.

Puglisi, R. and J. M. Snyder (2011). Newspaper coverage of political scandals. Journal of Politics 73(3), 931-950.

Raitano, M. and R. Fantozzi (2015). Political cycle and reported labour incomes in italy: Quasi-experimental evidence on tax evasion. European Journal of Political Economy 39, 269-280.

Rogoff, K. (1990). Equilibrium political budget cycles. American Economic Review 80(1), $21-36$.

Rogoff, K. and A. Sibert (1988). Elections and macroeconomic policy cycles. Review of Economic Studies 55(1), 1-16.

Sen, A. and P. Yildirim (2015). Clicks and editorial decisions: How does popularity shape online news coverage? Mimeo. Available at SSRN.

Shi, M. and J. Svensson (2006). Political budget cycles: Do they differ across countries and why? Journal of Public Economics 90(8/9), 1367-1389. 
Sidorkin, O. and D. Vorobyev (2017). Political cycles and corruption in russian regions. European Journal of Political Economy forthcoming.

Sobbrio, F. (2014a). Citizen-editors' endogenous information acquisition and news accuracy. Journal of Public Economics 113(1043), 43-53.

Sobbrio, F. (2014b). The political economy of news media: Theory, evidence and open issues. In F. Forte, R. Mudambi, and P. M. Navarra (Eds.), Handbook of Alternative Theories of Public Economics. Chelthenam: Edward Elgar Press.

Turati, G. (2013). The italian servizio sanitario nazionale: a renewing tale of lost promises. In J. Costa, , and S. L. Greer (Eds.), Federalism and Decentralization in European Health and Social Care: Competition, Innovation, and Cohesion, pp. 47-66. Palgrave MacMillan UK.

Tversky, A. and E. Shafir (1992). Thinking through uncertainty: Nonconsequential reasoning and choice. Cognitive Psychology 24, 449-474.

Vian, T. (2008). Review of corruption in the health sector: theory, methods, and intervention. Health Policy and Planning 23(2), 83-94. 


\section{Appendix A}

This Appendix describes in details the searching procedure applied to the Factiva archive in order to collect all the articles produced by La Repubblica, Il Giornale and Il Corriere della Sera about corruption scandals related to the NHS within the Italian regions. We accessed the Factiva database during the last week of April 2014, collecting all the articles appearing up to this date. For selecting the articles we firstly created two lists of Italian words, one related to the health system and the other to corruption. We then made a search on the Factiva database, exploiting its own searching tool and employing each time as keywords a different pair of words included in these lists, one from each, and we selected all the articles published by the three Italian newspapers containing both words in each combination. The semantic list concerning the health system included four words, that is "Sanitá" (health system), "SSN" (NHS), "ospedale/i" (hospital(s)). The semantic list related to corruption contained eleven words, that is "corruzione" (corruption), "scandalo/ $i$ " (scandal(s)), "tangente/i" (bribe(s)), "mazzetta/e" (bribe(s)), "appalto/i truccato/i" (rigged contract(s)) and "rimborso/i falso/i" (fraudulent reimbursement(s)).

Once the articles have been selected, we dropped all those not strictly concerning the corruption in the Italian NHS by a direct reading of each of them. For instance, we excluded those actually including a specific pair of keywords but in a different context (as for instance within a film review), or those about corruption scandals happening abroad. Since several articles contain at the same time different pairs of keywords, they appear more than once among the ones selected with our procedure; thus, we also dropped all duplicates from the sample.

For each article we collect the following information:

- The name of the newspaper producing the article;

- The date of the article (day/month/year);

- The specific case of corruption which the article refers to;

- The reference region of the case of corruption which the article refers to; 
- If the case of corruption involves politicians;

- The political orientation of the individual(s) involved in the corruption scandal (leftwing or right-wing).

According to such information, we drop from the final sample also the articles not referring to any specific case of corruption in the NHS, and those about nationwide corruption scandals. Lastly, we drop all the articles concerning cases of corruption discovered before the inclusion of the Corriere della Sera in the Factiva database (i.e. before 1997). 


\section{Appendix B}

The following list reports all the variables employed in the analysis presented in this paper, their description and the source(s) from which we collected the necessary information for their definition.

- Articles $\mathbf{i j t}_{\mathbf{i j t}}^{\mathbf{c}}$ : The number of articles produced at the date $t$ (day/month/year) by the newspaper $i$ (La Repubblica or Il Giornale) about corruption scandals with political orientation $c$ (left episodes, right episodes, no political episodes) related to the NHS in the Italian region $j$. The information for building this variable is retrieved from the Factiva database, as described in details in the Appendix A. In particular we collect all the articles produced by the two newspapers since they have started to digitalize them, which correspond to 2002 for Il Giornale and 2005 for La Repubblica, up to the date of our access to the Factiva database, that is the last week of April 2014.

- $\mathbf{R e p}_{\mathbf{i}}$ : A dummy variable equal to 1 if the observation at the date $t$ is related to La Repubblica and 0 otherwise. The information for constructing this variable is retrieved for the Factiva database, as described in details the Appendix A.

- Election $_{j t}$ : A dummy variable equal to 1 if the observation at the date $t$ (day/ month/year) is within 14 days (two weeks) from the next electoral round in the Italian region $j$ and 0 otherwise. For constructing this variable we matched the information about the dates of the articles derived from the Factiva database with the information concerning regional elections within each Italian region, as provided by the Italian Ministry of Internal Affairs via its official web page.

- OldEpisodes $\mathbf{j}_{\mathbf{j}}^{\mathbf{c}}$ : The number of cases of corruption in the NHS with political orientation $c$ (left episodes, right episodes, no political episodes) in the region $j$ already discovered up to the date $t$ (day/month/year). We consider as already discovered all those corruption scandals which appear at least once before the date $t$ in our sample of articles derived from the Factiva database (including also Il Corriere della Sera). 
- NewEpisodes $\mathbf{j}_{\mathbf{j} t}^{\mathbf{c}}$ : The number of cases of corruption in the NHS with political orientation $c$ (left episodes, right episodes, no political episodes) in the region $j$ discovered at the date $t$ (day/month/year). We consider as discovered at the date $t$ all those corruption scandals which appear for the first time at the date $t$ in our sample of articles derived from the Factiva database (including also Il Corriere della Sera).

- Corriere $\mathbf{i j j}_{\mathbf{j} \mathbf{t}}^{\mathbf{c}}$ : The number of articles produced at the date $t$ (day/month/year) by Il Corriere della Sera about corruption scandals with political orientation $c$ (left episodes, right episodes, no political episodes) related to the NHS in the Italian region $j$. The information for constructing this variable is retrieved for the Factiva database, as described in details in the Appendix A. In particular we collect all the articles produced by this newspaper from the beginning of January 2002 to the end of April 2014.

- RGovernor Rt $_{j}$ A dummy variable equal to 1 if the incumbent governor of region $j$ at the date $t$ (day/month/year) belongs to the Italian right-wing party and 0 otherwise. For constructing this variable we matched the information about the dates of the articles derived from the Factiva database with the information concerning regional elections in each Italian region, as provided by the Italian Ministry of Internal Affairs through its official web page.

- Mandates ${ }_{j t}$ : The number of consecutive mandates run by the incumbent governor of the Italian region $j$ at the date $t$ (day/month/year). For constructing this variable we matched the information about the dates of the articles derived from the Factiva database with the information concerning regional elections in each Italian region, as provided by the Italian Ministry of Internal Affairs through its official web page.

- RPrime : $_{t}$ A dummy variable equal to 1 if the incumbent Italian Prime Minister at the date $t$ (day/month/year) belongs to the Italian right-wing part and 0 otherwise. For constructing this variable we matched the information about the dates of the articles derived from the Factiva database with the information concerning regional 
elections in each Italian region, as provided by the Italian Ministry of Internal Affairs through its official web page.

- Turnover $_{i(y-1)}$ : The total turnover of newspaper $i$ (La Repubblica or Il Giornale) in the year $y-1$ expressed in logarithmic scale. We derive the information for constructing this variable from the report "La Stampa in Italia" produced yearly by Federazione Italiana Editori Giornali (FIEG). The raw information is available for all the years in the interval 2002-2012. We impute the value for 2013 and 2014 using the average between the values recorded during the five years before.

- Diffusion ${ }_{i j(y-1)}$ : The ratio between the newspaper $i$ 's number of copies sold in region $j$ and the total number of copies sold over the entire Italian territory in the year $y$-1. We derive the information for constructing this variable directly from the web page of the Accertamenti Diffusione Stampa (ADS), which provides such information for all the years within the interval 2002-2014.

- HealthExpXCapita ${ }_{j y}$ : A dummy variable equal to 1 if the the public health expenditure per capita in region $j$ is above the national average in the year $y$ and 0 otherwise. The information for constructing the variable is directly derived for all the years within the interval 2002-2014 from the database "Health for All" produced by the ISTAT.

- SecExpXCapita ${ }_{j y}$ : A dummy variable equal to 1 if the the public expenditure for law and order per capita in region $j$ is above the national average in the year $y$ and 0 otherwise. The information for constructing the variable is directly derived from the database "I.Stat" produced by the ISTAT for all the years within the interval 2002-2012. We impute the values for 2013 and 2014 with the average between the values recorded during the five years before.

- NPages ${ }_{i}$ : The average number of pages included in each newspaper along the period 2002-2014. We use this variable as exposure variable in the Negative Binomial regression model presented in section 5.2. The value for this variable correspond to 
60 for La Repubblica and 40 for Il Giornale and they rely on our own calculation on the information provided within the Factiva archive. 



\section{Working Paper del Dipartimento di Economia e Finanza}

1. L. Colombo, H. Dawid, Strategic Location Choice under Dynamic Oligopolistic Competition and Spillovers, novembre 2013.

2. M. Bordignon, M. Gamalerio, G. Turati, Decentralization, Vertical Fiscal Imbalance, and Political Selection, novembre 2013.

3. M. Guerini, Is the Friedman Rule Stabilizing? Some Unpleasant Results in a Heterogeneous Expectations Framework, novembre 2013.

4. E. Brenna, C. Di Novi, Is caring for elderly parents detrimental to women's mental health? The influence of the European North-South gradient, novembre 2013.

5. F. Sobbrio, Citizen-Editors' Endogenous Information Acquisition and News Accuracy, novembre 2013.

6. P. Bingley, L. Cappellari, Correlation of Brothers Earnings and Intergenerational Transmission, novembre 2013.

7. T. Assenza, W. A. Brock, C. H. Hommes, Animal Spirits, Heterogeneous Expectations and the Emergence of Booms and Busts, dicembre 2013.

8. D. Parisi, Is There Room for 'Fear' as a Human Passion in the Work by Adam Smith?, gennaio 2014

9. E. Brenna, F. Spandonaro, Does federalism induce patients' mobility across regions? Evidence from the Italian experience, febbraio 2014.

10. A. Monticini, F. Ravazzolo, Forecasting the intraday market price of money, febbraio 2014.

11. Tiziana Assenza, Jakob Grazzini, Cars Hommes, Domenico Massaro, PQ Strategies in Monopolistic Competition: Some Insights from the Lab, marzo 2014.

12. R. Davidson, A. Monticini, Heteroskedasticity-and-Autocorrelation-Consistent Bootstrapping, marzo 2014.

13. C. Lucifora, S. Moriconi, Policy Myopia and Labour Market Institutions, giugno 2014.

14. N. Pecora, A. Spelta, Shareholding Network in the Euro Area Banking Market, giugno 2014.

15. G. Mazzolini, The economic consequences of accidents at work, giugno 2014.

16. M. Ambrosanio, P. Balduzzi, M. Bordignon, Economic crisis and fiscal federalism in Italy, settembre 2014.

17. P. Bingley, L. Cappellari, K. Tatsiramos, Family, Community and Long-Term Earnings Inequality, ottobre 2014.

18. S. Frazzoni, M. L. Mancusi, Z. Rotondi, M. Sobrero, A. Vezzulli, Innovation and export in SMEs: the role of relationship banking, novembre 2014.

19. H. Gnutzmann, Price Discrimination in Asymmetric Industries: Implications for Competition and Welfare, novembre 2014.

20. A. Baglioni, A. Boitani, M. Bordignon, Labor mobility and fiscal policy in a currency union, novembre 2014.

21. C. Nielsen, Rational Overconfidence and Social Security, dicembre 2014.

22. M. Kurz, M. Motolese, G. Piccillo, H. Wu, Monetary Policy with Diverse Private Expectations, febbraio 2015.

23. S. Piccolo, P. Tedeschi, G. Ursino, How Limiting Deceptive Practices Harms Consumers, maggio 2015.

24. A.K.S. Chand, S. Currarini, G. Ursino, Cheap Talk with Correlated Signals, maggio 2015.

25. S. Piccolo, P. Tedeschi, G. Ursino, Deceptive Advertising with Rational Buyers, giugno 2015. 
26. S. Piccolo, E. Tarantino, G. Ursino, The Value of Transparency in Multidivisional Firms, giugno 2015.

27. G. Ursino, Supply Chain Control: a Theory of Vertical Integration, giugno 2015.

28. I. Aldasoro, D. Delli Gatti, E. Faia, Bank Networks: Contagion, Systemic Risk and Prudential Policy, luglio 2015.

29. S. Moriconi, G. Peri, Country-Specific Preferences and Employment Rates in Europe, settembre 2015.

30. R. Crinò, L. Ogliari, Financial Frictions, Product Quality, and International Trade, settembre 2015.

31. J. Grazzini, A. Spelta, An empirical analysis of the global input-output network and its evolution, ottobre 2015.

32. L. Cappellari, A. Di Paolo, Bilingual Schooling and Earnings: Evidence from a Languagein-Education Reform, novembre 2015.

33. A. Litina, S. Moriconi, S. Zanaj, The Cultural Transmission of Environmental Preferences: Evidence from International Migration, novembre 2015.

34. S. Moriconi, P. M. Picard, S. Zanaj, Commodity Taxation and Regulatory Competition, novembre 2015.

35. M. Bordignon, V. Grembi, S. Piazza, Who do you blame in local finance? An analysis of municipal financing in Italy, dicembre 2015.

36. A. Spelta, A unified view of systemic risk: detecting SIFIs and forecasting the financial cycle via EWSs, gennaio 2016.

37. N. Pecora, A. Spelta, Discovering SIFIs in interbank communities, febbraio 2016.

38. M. Botta, L. Colombo, Macroeconomic and Institutional Determinants of Capital Structure Decisions, aprile 2016.

39. A. Gamba, G. Immordino, S. Piccolo, Organized Crime and the Bright Side of Subversion of Law, maggio 2016.

40. L. Corno, N. Hildebrandt, A. Voena, Weather Shocks, Age of Marriage and the Direction of Marriage Payments, maggio 2016.

41. A. Spelta, Stock prices prediction via tensor decomposition and links forecast, maggio 2016.

42. T. Assenza, D. Delli Gatti, J. Grazzini, G. Ricchiuti, Heterogeneous Firms and International Trade: The role of productivity and financial fragility, giugno 2016.

43. S. Moriconi, Taxation, industry integration and production efficiency, giugno 2016.

44. L. Fiorito, C. Orsi, Survival Value and a Robust, Practical, Joyless Individualism: Thomas Nixon Carver, Social Justice, and Eugenics, luglio 2016.

45. E. Cottini, P. Ghinetti, Employment insecurity and employees' health in Denmark, settembre 2016.

46. G. Cecere, N. Corrocher, M. L. Mancusi, Financial constraints and public funding for ecoinnovation: Empirical evidence on European SMEs, settembre 2016.

47. E. Brenna, L. Gitto, Financing elderly care in Italy and Europe. Is there a common vision?, settembre 2016.

48. D. G. C. Britto, Unemployment Insurance and the Duration of Employment: Theory and Evidence from a Regression Kink Design, settembre 2016.

49. E. Caroli, C.Lucifora, D. Vigani, Is there a Retirement-Health Care utilization puzzle? Evidence from SHARE data in Europe, ottobre 2016.

50. G. Femminis, From simple growth to numerical simulations: A primer in dynamic programming, ottobre 2016.

51. C. Lucifora, M. Tonello, Monitoring and sanctioning cheating at school: What works? Evidence from a national evaluation program, ottobre 2016. 
52. A. Baglioni, M. Esposito, Modigliani-Miller Doesn't Hold in a "Bailinable” World: A New Capital Structure to Reduce the Banks' Funding Cost, novembre 2016.

53. L. Cappellari, P. Castelnovo, D. Checchi, M. Leonardi, Skilled or educated? Educational reforms, human capital and earnings, novembre 2016.

54. D. Britto, S. Fiorin, Corruption and Legislature Size: Evidence from Brazil, dicembre 2016.

55. F. Andreoli, E. Peluso, So close yet so unequal: Reconsidering spatial inequality in U.S. cities, febbraio 2017.

56. E. Cottini, P. Ghinetti, Is it the way you live or the job you have? Health effects of lifestyles and working conditions, marzo 2017.

57. A. Albanese, L. Cappellari, M. Leonardi, The Effects of Youth Labor Market Reforms: Evidence from Italian Apprenticeships; maggio 2017.

58. S. Perdichizzi, Estimating Fiscal multipliers in the Eurozone. A Nonlinear Panel Data Approach, maggio 2017.

59. S. Perdichizzi, The impact of ECBs conventional and unconventional monetary policies on European banking indexes returns, maggio 2017.

60. E. Brenna, Healthcare tax credits: financial help to taxpayers or support to higher income and better educated patients? Evidence from Italy, giugno 2017.

61. G. Gokmen, T. Nannicini, M. G. Onorato, C. Papageorgiou, Policies in Hard Times: Assessing the Impact of Financial Crises on Structural Reforms, settembre 2017.

62. M. Tettamanzi, E Many Pluribus Unum: A Behavioural Macro-Economic Agent Based Model, novembre 2017.

63. A. Boitani, C. Punzo, Banks' leverage behaviour in a two-agent New Keynesian model, gennaio 2018.

64. M. Bertoni, G. Brunello, L. Cappellari, Parents, Siblings and Schoolmates. The Effects of Family-School Interactions on Educational Achievement and Long-term Labor Market Outcomes, gennaio 2018.

65. G. P. Barbetta, G. Sorrenti, G. Turati, Multigrading and Child Achievement, gennaio 2018.

66. S. Gagliarducci, M. G. Onorato, F. Sobbrio, G. Tabellini, War of the Waves: Radio and Resistance During World War II, febbraio 2018.

67. P. Bingley, L. Cappellari, Workers, Firms and Life-Cycle Wage Dynamics, marzo 2018.

68. A. Boitani, S. Perdichizzi, Public Expenditure Multipliers in recessions. Evidence from the Eurozone, marzo 2018.

69. M. Le Moglie, G. Turati, Electoral Cycle Bias in the Media Coverage of Corruption News, aprile 2018. 